\title{
Extraction of $\beta$-sitosterol from Swietenia mahagoni seeds by using supercritical carbon dioxide $\left(\mathrm{SC}-\mathrm{CO}_{2}\right)$ extraction
}

\author{
Nur Salsabila Md Norodin a, b, Liza Md Salleh a, b, *, Siti Machmudah c, Nik Musaadah Mustafa d, \\ Hartati ${ }^{\mathrm{e}}$, Ramdan Ismail a, b \\ a Center of Lipids Engineering and Applied Research (CLEAR), Ibnu Sina Institute Scientific \& Industrial Research (Ibnu Sina ISIR), Universiti \\ Teknologi Malaysia, 81300 Johor Bahru, Johor, Malaysia \\ b Department of Bioprocess and Polymer Engineering, Faculty of Chemical and Energy Engineering, UniversitiTeknologi Malaysia, 81310 UTM \\ Johor Bahru, Johor, Malaysia \\ c Chemical Engineering Department, Sepuluh Nopember Institute of Technology, 60111 Surabaya, Indonesia \\ d Natural Product Division, Forest Research Institute Malaysia (FRIM), 52109 Kepong, Selangor Darul Ehsan, Malaysia \\ e Department of Biology, Universitas Negeri Makassar, South Sulawesi, Indonesia \\ *Corresponding author: i.liza@cheme.utm.my
}

\section{Article history}

Submitted 6 March 2018

Revised 19 March 2018

Accepted 1 April 2018

Published Online 3 September 2018

\section{Graphical abstract}

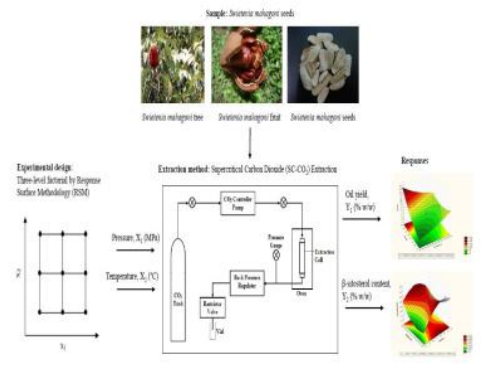

\section{Abstract}

This work investigates the effect of supercritical carbon dioxide $\left(\mathrm{SC}-\mathrm{CO}_{2}\right)$ extraction conditions (pressure and temperature) on the oil yield and $\beta$-sitosterol content extracted from Swietenia mahagoni seeds by using response surface methodology (RSM). The experimental data obtained were fitted to a secondorder polynomial model and the obtained oil yields were $1.49-14.45 \%$, while $\beta$-sitosterol content obtained were $3.12-9.20 \mathrm{mg} / \mathrm{g}$. The best conditions within the ranges studied were $30 \mathrm{MPa}$ and $40^{\circ} \mathrm{C}$ to extract $\beta$ sitosterol in the highest amount. The present findings show that $S$. mahagoni seeds extract has a high concentration of $\beta$-sitosterol.

Keywords: Swietenia mahagoni seeds, $\beta$-sitosterol, supercritical $\mathrm{CO}_{2}$ extraction, response surface methodology

\section{INTRODUCTION}

Swietenia mahagoni is also known as 'tunjuk langit' in Malaysia (Fig. 1) is used traditionally to treat various diseases such as diabetes and high blood pressure (Goh et al., 2010). Swietenia mahagoni tree is 30 meters or taller (Eid et al., 2013) and the wood, usually being used for making furniture (Falah et al., 2008). Meanwhile, the bark can be used for natural colorant (Haque et al., 2013). The fruit of Swietenia mahagoni is woody and consisting of capsules containing winged seeds (Blundell et al., 2003). Whereas, the seed of Swietenia mahagoni can be obtained by removing the wing. In Malaysia, the raw seeds were used for treating hypertension and diabetes (Balijepalli et al., 2014). In addition, Swietenia mahagoni seeds have been reported to have various biological activities such as anti-inflammatory activity, anticancer and antitumor activity (Goh et al., 2011) and also antidiabetic activity (Maiti et al., 2009). Moreover, the seeds contain a number of bioactive compounds as has been noted by Hashim et al., (2013) and presented in Table 1 .

To date, no study was found on the quantification of $\beta$-sitosterol from Swietenia mahagoni seeds using high performance liquid chromatography (HPLC). Recently, attention on the importance of natural compounds from plants and herbs has been reassessing. As a matter of fact, bioactive compounds from plant sources are chemically sensitive and present in low concentration, hence supercritical carbon dioxide $\left(\mathrm{SC}-\mathrm{CO}_{2}\right)$ extraction is an appropriate extraction method to use. $\mathrm{SC}-\mathrm{CO}_{2}$ is a separation process of matters by using supercritical carbon dioxide as a solvent. In this case, thermolabile and non-polar compounds can be extracted by using $\mathrm{SC}-\mathrm{CO}_{2}$ extraction due to the low operating temperature of $30^{\circ} \mathrm{C}$ without any degradation. It cannot be used to extract polar compounds since $\mathrm{SC}-\mathrm{CO}_{2}$ extraction is more appropriate to extract non-polar nature compounds (Vilegas et al., 1997). Previously, $\beta$-sitosterol has been extracted from various plants using $\mathrm{SC}-\mathrm{CO}_{2}$ since $\beta$-sitosterol is a non-polar compound. Therefore, no co-solvent is needed in the extraction of $\beta$-sitosterol by using SC$\mathrm{CO}_{2}$ extraction.

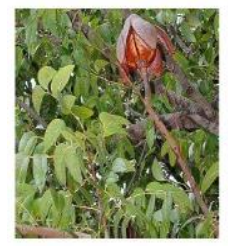

(a)

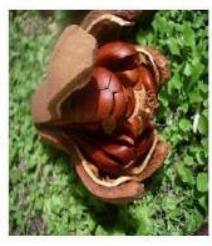

(b)

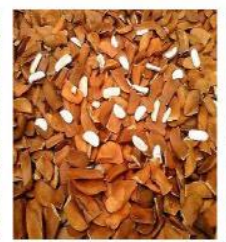

(c)

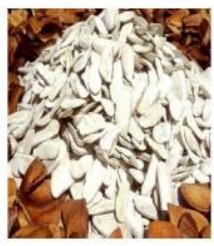

(d)
Fig. 1 Swietenia mahagoni also known as 'tunjuk langit' in Malaysia (a) tree, (b) fruit, (c) winged seeds and (d) seeds.

Moreover, carbon dioxide $\left(\mathrm{CO}_{2}\right)$ is the most frequently solvent used because it is environmental friendly (fairly non-toxic), low cost and can be easily removed from the extract (Liza et al., 2010). The elimination of $\mathrm{CO}_{2}$ is easily achieved since $\mathrm{CO}_{2}$ is in a gas state at room 
temperature. In addition, $\mathrm{CO}_{2}$ in the supercritical state is in a moderate critical temperature $\left(31.3^{\circ} \mathrm{C}\right)$ and pressure $(7.38 \mathrm{MPa})$. Supercritical state is when gas and liquid are indistinguishable where at this state it is compressible but possessing a density of a liquid. In a word, supercritical $\mathrm{CO}_{2}$ makes a good solvent because of the gas-like state that attributed the low viscosity and high diffusion coefficient and the liquid-like state that gave the solvating power (Aionicesei et al., 2008).

Table 1 Primary compounds found in S. mahagoni seeds determined by gas chromatography-mass spectrometry (Hashim et al., (2013).

\begin{tabular}{ll}
\hline Compounds & $\begin{array}{c}\text { Molecular } \\
\text { formula }\end{array}$ \\
\hline Hexadecanoic acid, methyl ester & $\mathrm{C}_{17} \mathrm{H}_{34} \mathrm{O}_{2}$ \\
n-Hexadecanoic acid & $\mathrm{C}_{16} \mathrm{H}_{32} \mathrm{O}_{2}$ \\
9-Octadecenoic acid (Z)- methyl ester & $\mathrm{C}_{19} \mathrm{H}_{36} \mathrm{O}_{2}$ \\
9,12-Octadecadienoic acid (Z,Z)-Linoleic acid & $\mathrm{C}_{18} \mathrm{H}_{32} \mathrm{O}_{2}$ \\
Gamma-tocopherol & $\mathrm{C}_{28} \mathrm{H}_{48} \mathrm{O}_{2}$ \\
Fucosterol & $\mathrm{C}_{29} \mathrm{H}_{48} \mathrm{O}$ \\
$\beta$ - sitosterol & $\mathrm{C}_{29} \mathrm{H}_{50} \mathrm{O}$ \\
\hline
\end{tabular}

Furthermore, the extraction of $\beta$-sitosterol from various plants using $\mathrm{SC}-\mathrm{CO}_{2}$ extraction have been reported in the extraction of saw palmetto berries (Catchpole et al., 2002), Vitex agnus castus fruit (Cossuta et al., 2008) and sea buckthorn seeds (Sajfrtová et al., 2010). Sajfrtová et al., (2010) has reported that low temperature in the extraction of $\beta$-sitosterol as low as $50^{\circ} \mathrm{C}$ didn't cause the degradation of $\beta$-sitosterol since the degradation was occurred at temperature exceeding the temperature mentioned. Also, the yield of $\beta$-sitosterol increased slightly as pressure increased and the highest yield found from Vitex agnus castus fruit was $1.1 \mathrm{mg} / \mathrm{g}$ at a pressure of $45 \mathrm{MPa}$ and a temperature of $40^{\circ} \mathrm{C}$ (Cossuta et al., 2008). In this context, the extraction of $\beta$-sitosterol can be manipulated or controlled by pressure and temperature. Pressure and temperature are the most relevant parameters in supercritical carbon dioxide $\left(\mathrm{SC}-\mathrm{CO}_{2}\right)$ extraction. In general, quantitative recovery of analytes influence by the increase in pressure lead to the increase in solvent power. Solvent power is described as the solvent density in any given conditions. Significantly, high pressure and moderate temperature favor the extraction of $\beta$ sitosterol from plants using $\mathrm{SC}-\mathrm{CO}_{2}$.

Therefore, the aim of this work is to determine the effect of pressure and temperature of supercritical carbon dioxide $\left(\mathrm{SC}-\mathrm{CO}_{2}\right)$ extraction on the oil yield and $\beta$-sitosterol content from Swietenia mahagoni seeds by using response surface methodology (RSM).

\section{EXPERIMENTAL}

\section{Materials}

Swietenia mahagoni seeds were bought in the local market of Johor, Malaysia. Commercial grade liquid carbon dioxide (purity 99.99\%) used in $\mathrm{SC}-\mathrm{CO}_{2}$ extraction was purchased from Kras, Instrument and Services, Johor, Malaysia. Methanol grade HPLC and $\beta$-sitosterol standard were purchased from Sigma-Aldrich, Germany

\section{Sample preparation}

The seeds were rinsed with tap water to remove any foreign particles and dirt prior to drying. Then, the cleaned seeds were cut into small pieces and dried by using oven at temperature of $50^{\circ} \mathrm{C}$ for a week to remove moistures. The seeds were ground by using a blender (Waring ${ }^{\circledR}$ Commercial blender) and sieved to approximately $0.50 \mathrm{~mm}$ of particle size.

\section{Supercritical carbon dioxide $\left(\mathrm{SC}-\mathrm{CO}_{2}\right)$ extraction}

Supercritical fluid extraction (SFE) machine in Center of Lipids Engineering and Applied Research (CLEAR), Universiti Teknologi Malaysia is consisted of $\mathrm{CO}_{2}$ gas cylinder, $\mathrm{CO}_{2}$ controller pump (Lab Alliance), co-solvent pump (Lab Alliance), oven (Memmert, Germany), $10 \mathrm{ml}$ stainless steel extraction vessel, pressure gauge (Swagelockk, Germany), automatic back pressure regulator (Jasco BP 2080- Plus) and restrictor valve. A schematic diagram of CLEAR SFE apparatus is illustrated in Fig. 2.

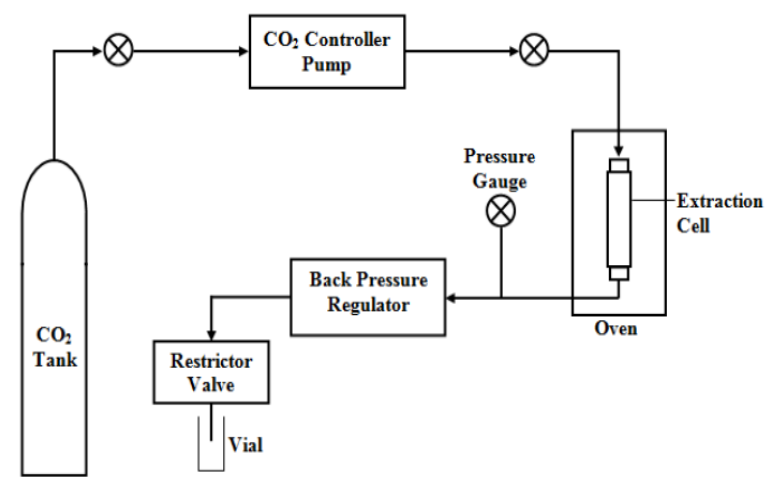

Fig. 2 Schematic diagram of CLEAR supercritical fluid extraction (SFE) machine

The parameters and constant parameters used in extraction process are presented in Table 2. Five gram of sample was placed in $10 \mathrm{ml}$ stainless steel extraction vessel and sealed tightly in the oven. All the parameters (temperature, pressure and flowrate of $\mathrm{CO}_{2}$ ) was fixed, and the extraction process was started after all the parameters were attained. The extract was collected by depressurizing the system. The oil yields were collected after 120 minute extraction time.

Table 2 The process parameters for $\mathrm{SC}-\mathrm{CO}_{2}$ extraction.

\begin{tabular}{cc}
\hline Parameter & Range/value \\
\hline Temperature $\left({ }^{\circ} \mathrm{C}\right)$ & $40-60$ \\
Pressure $(\mathrm{MPa})$ & $20-30$ \\
Flowrate of $\mathrm{CO}_{2}(\mathrm{ml} / \mathrm{min})$ & 2.00 \\
Particle size $(\mathrm{mm})$ & 0.50 \\
Mass of sample $(\mathrm{g})$ & 5.00 \\
Extraction time $(\mathrm{min})$ & 120 \\
\hline
\end{tabular}

The oil yield was calculated as percentage of oil yield using Eq. (1) as follow:

$$
\text { Oil Yield }(\%)=\left(\mathrm{M}_{0} / \mathrm{M}_{1}\right) \times 100
$$

where $\mathrm{M}_{0}$ is the mass of oil extract in gram and $\mathrm{M}_{1}$ is the mass of sample in gram.

\section{Design of experimental for response surface methodology (RSM)}

Response surface methodology (RSM) is a technique used to describe the behavior of a set of data. The main purpose is to optimize the variables so that the best system performance could be obtained. Three-level factorial design was employed to optimize the oil yield and $\beta$-sitosterol content from Swietenia mahagoni seed. The number of experiments is calculated by expression of Eq. (2) (Bezerra et al., 2008) below :

$$
N=3^{k}
$$

where $\mathrm{N}$ is the number of experiment and $\mathrm{k}$ is the number of factor.

Three-level factorial is suitable for second-order polynomial model of two factors. In supercritical fluid extraction, three level factorial usually been used to optimize the number of factors for obtaining the highest yield of extract (Sharif et al., 2014). The coded and un-coded values are shown in Table 3 . Moreover, the analysis of variance (ANOVA) and the regression analysis were all obtained by using Statistica software version 7.0 (STatSoft, EUA). ANOVA analysis was used to analyze the significance of the results at $95 \%$ of confidence level.

Table 3 The extraction process variables in coded and un-coded levels.

\begin{tabular}{ccc}
\hline \multirow{2}{*}{$\begin{array}{c}\text { Coded } \\
\text { factors level }\end{array}$} & \multicolumn{2}{c}{ Un-coded factors level } \\
\cline { 2 - 3 } & $\begin{array}{c}\text { Pressure, } \mathbf{X}_{\mathbf{1}} \\
(\mathbf{M P a})\end{array}$ & $\begin{array}{c}\text { Temperature, } \mathbf{X}_{\mathbf{2}} \\
\left({ }^{\circ} \mathbf{C}\right)\end{array}$ \\
\hline Low $(-1)$ & 20 & 40 \\
Middle $(0)$ & 25 & 50 \\
High $(+1)$ & 30 & 60 \\
\hline
\end{tabular}


High performance liquid chromatography (HPLC) analysis

Identification of $\beta$-sitosterol was conducted by using a Waters HPLC system (Milford, MA, USA) consisting of a pump and system controller (Model Waters e2695) with photo-diode array detector (Model 2998). The method of identification for $\beta$-sitosterol was referred to the previous method (Sánchez-Machado et al., 2004) with a slight modification. C18 reserved phase Kinetex Biphenyl column (5 $\mu \mathrm{m}, 4.6 \times 150 \mathrm{~mm}$ ) with a flow rate of $1.0 \mathrm{ml} / \mathrm{min}$ was used for compound separation. The mobile phase was consisted of methanol $(60 \%) /$ acetonitrile $(40 \%)$, in an isocratic program. The injection volume of sample was $20 \mu \mathrm{L}$ and all samples were filtered with 0.45 $\mu \mathrm{m}$ nylon filters prior to injection. The detection was monitored at 210 $\mathrm{nm}$ and data were integrated by Empower 3 software (Waters) (Milford, MA, USA).

\section{RESULTS AND DISCUSSION}

\section{$\beta$-sitosterol content}

The $\beta$-sitosterol content of Swietenia mahagoni seeds extract with different conditions in $\mathrm{SC}-\mathrm{CO}_{2}$ extraction were identified and quantified. The highest $\beta$-sitosterol content was $9.2 \mathrm{mg} / \mathrm{g}$ obtained at $30 \mathrm{MPa}$ and $40^{\circ} \mathrm{C}$, meanwhile the lowest one $(3.12 \mathrm{mg} / \mathrm{g})$ was obtained at $20 \mathrm{MPa}$ and $50^{\circ} \mathrm{C}$. Previous researches on the $\beta$-sitosterol content of other plants using $\mathrm{SC}-\mathrm{CO}_{2}$ extraction were compared with the result in this study as shown in Table 4 . Notably, the temperature of $40^{\circ} \mathrm{C}$ shows better extraction of $\beta$-sitosterol from plants since low temperature can avoid the degradation of compound. The temperature in $\mathrm{SC}-\mathrm{CO}_{2}$ extraction influenced the yield of $\beta$-sitosterol because of the solvent density changed. The solvent density increases with decreasing temperature, hence the solubility of $\beta$-sitosterol increases by increasing the solvating power. Moreover, high pressure also increased the solvent density.

This finding is accordance with previous researches in the extraction of $\beta$-sitosterol by using SC- $\mathrm{CO}_{2}$ extraction (Catchpole et al., 2002, Simandi et al., 2002, Andras et al., 2005, Cossuta et al., 2008). Catchpole et al., (2002) reported the extraction of $\beta$-sitosterol from saw palmetto berries using $\mathrm{SC}-\mathrm{CO}_{2}$ at pressures of 25 and $28 \mathrm{MPa}$ and temperature of $40^{\circ} \mathrm{C}$. The maximum $\beta$-sitosterol content was achieved at $28 \mathrm{MPa}$ and $40^{\circ} \mathrm{C}$. It can be stated that high pressure and low temperature favor to be applied in the extraction of $\beta$-sitosterol from plants. Fig. 3 and 4 shows the HPLC chromatograms of the standard
( $\beta$-sitosterol) at a concentration of $80 \mathrm{ppm}$ and $\beta$-sitosterol compound detected in Swietenia mahagoni oil extract, respectively.

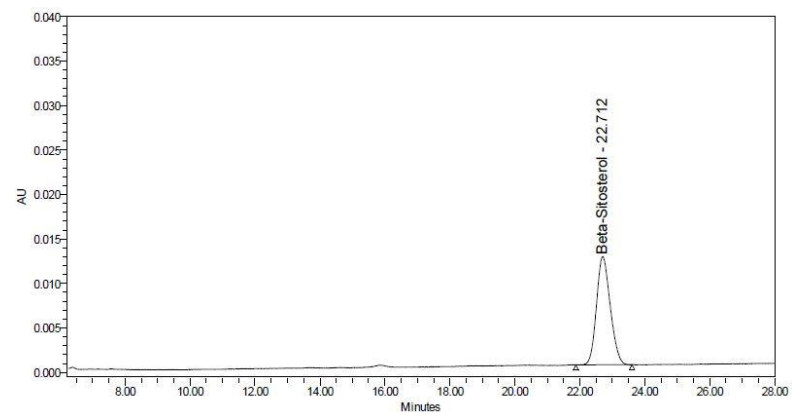

Fig. 3 HPLC chromatogram of the standard ( $\beta$-sitosterol) at concentration of $80 \mathrm{ppm}$

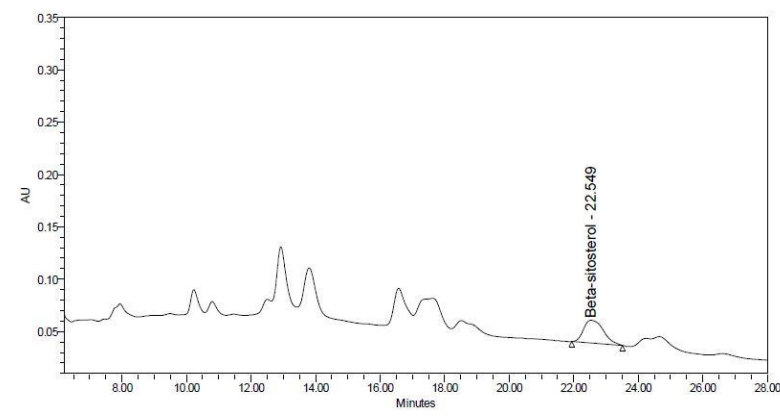

Fig. 4 HPLC chromatogram of $\beta$-sitosterol compound detected in $S$. mahagoni oil extracted at $30 \mathrm{MPa}$ and $40^{\circ} \mathrm{C}$

\section{Optimization of supercritical carbon dioxide $\left(\mathrm{SC}-\mathrm{CO}_{2}\right)$ extraction}

Optimization in experimental design for supercritical fluid extraction referred to as a separation performance to achieve high extraction efficiency by improving different operating conditions of various processes (Sharif et al., 2014). Experimental design for Swietenia mahagoni seed was based on three level factorial with 13 set of experiments with four repetition at middle point, as shown on Table 5 .

Table 4 Extraction of $\beta$-sitosterol by SC- $\mathrm{CO}_{2}$ extraction.

\begin{tabular}{|c|c|c|c|c|}
\hline \multirow[b]{2}{*}{ Raw material } & \multicolumn{2}{|c|}{ Extraction conditions } & \multirow[b]{2}{*}{$\begin{array}{c}\beta \text {-sitosterol content } \\
(\mathrm{mg} / \mathrm{g})\end{array}$} & \multirow[b]{2}{*}{ Reference } \\
\hline & $\begin{array}{c}\text { Pressure } \\
\text { (MPa) }\end{array}$ & $\begin{array}{c}\text { Temperature } \\
\left({ }^{\circ} \mathrm{C}\right)\end{array}$ & & \\
\hline Saw palmetto berries & 28 & 40 & 2.3 & [13] \\
\hline Vitex agnus castus fruit & 45 & 40 & 1.1 & [14] \\
\hline Sea Buckthorn seeds & 15 & 40 & 5.0 & [15] \\
\hline Swietenia mahagoni seeds & 30 & 40 & 9.2 & This study \\
\hline
\end{tabular}

Table 5 Experimental matrix and values of the observed responses

\begin{tabular}{ccccccccc}
\hline \multirow{2}{*}{ Run } & $\begin{array}{c}\text { Pressure, } \\
\mathbf{X}_{\mathbf{1}}(\mathbf{M P a})\end{array}$ & $\begin{array}{c}\text { Temperature, } \\
\mathbf{X}_{\mathbf{2}}\left({ }^{\circ} \mathbf{C}\right)\end{array}$ & \multicolumn{2}{c}{ Coded level } & \multicolumn{2}{c}{ Extraction yield (\%) } & \multicolumn{2}{c}{$\boldsymbol{\beta}$-sitosterol concentration (\%) } \\
\cline { 6 - 8 } & $\mathbf{1}$ & 40 & -1 & -1 & 6.56 & 7.28 & 0.35 & 0.35 \\
$\mathbf{2}$ & 20 & 50 & -1 & 0 & 3.68 & 3.31 & 0.31 & 0.27 \\
$\mathbf{3}$ & 20 & 60 & -1 & +1 & 1.49 & 1.13 & 0.59 & 0.64 \\
$\mathbf{4}$ & 20 & 40 & 0 & -1 & 6.64 & 5.78 & 0.70 & 0.81 \\
$\mathbf{5}$ & 25 & 50 & 0 & 0 & 4.79 & 4.93 & 0.56 & 0.61 \\
$\mathbf{6}$ & 25 & 60 & 0 & +1 & 4.56 & 5.87 & 0.87 & 0.86 \\
$\mathbf{7}$ & 25 & 40 & +1 & -1 & 7.02 & 7.16 & 0.92 & 0.82 \\
$\mathbf{8}$ & 30 & 50 & +1 & 0 & 8.61 & 9.43 & 0.37 & 0.50 \\
$\mathbf{9}$ & 30 & 60 & +1 & +1 & 14.45 & 13.50 & 0.67 & 0.63 \\
$\mathbf{1 0}$ & 30 & 50 & 0 & 0 & 4.95 & 4.93 & 0.56 & 0.61 \\
$\mathbf{1 1}$ & 25 & 50 & 0 & 0 & 6.03 & 4.93 & 0.69 & 0.61 \\
$\mathbf{1 2}$ & 25 & 50 & 0 & 0 & 5.06 & 4.93 & 0.64 & 0.61 \\
$\mathbf{1 3}$ & 25 & 50 & 0 & 0 & 4.28 & 4.93 & 0.67 & 0.61 \\
\hline
\end{tabular}




\section{Fitting the response surface model}

The selection of a model for the experimental data was selected based on correlation coefficient $\left(\mathrm{R}^{2}\right)$ and Fisher F-test (Rastogi et al., 1999). In addition, $R^{2}$ can be expressed as a proportion of variance in a set of data explained by a statistical model. When $\mathrm{R}^{2}$ value approaching or approximately 1 , the model can be said well fitted to the actual data (Sin et al., 2006). Typically, $\mathrm{R}^{2}$ value more than 0.75 is considered accurate in developing statistical model or equation (Henika., 1982). Fig. 5 and 6 are illustration of the experimental data (observed) and predicted values of oil yield and $\beta$-sitosterol content, respectively. The $\mathrm{R}^{2}$ values for oil yield and $\beta$-sitosterol concentration at $95 \%$ confident level were 0.94 and 0.85 , respectively.

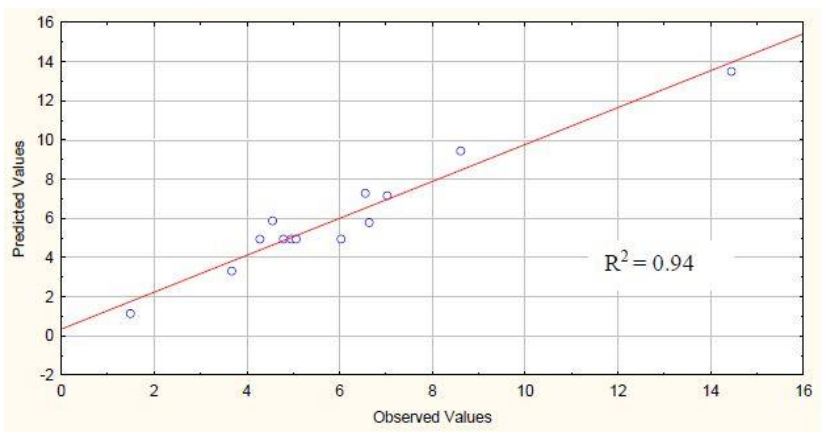

Fig. 5 Experimental data (observed) versus predicted values for $S$. mahagoni seeds oil yield

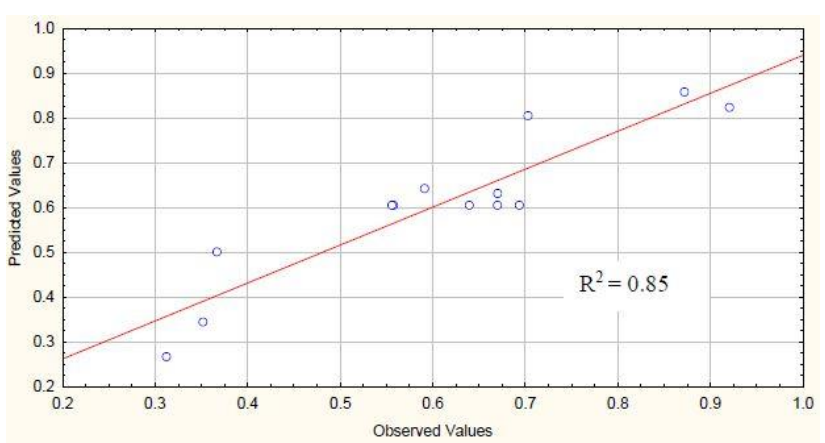

Fig. 6 Experimental data (observed) versus predicted values for $\beta$ sitosterol

Furthermore, the F-calculated values from ANOVA for oil yield and $\beta$-sitosterol content were also considered in selecting an adequate model for the process. Table 6 and 7 show the analysis of variance for oil yield and $\beta$-sitosterol, respectively, fitted in the second-order polynomial model. The calculated F-value defined as the ratio of the mean square of model or regression to the mean square of residual. The larger the F-value, the greater significance of the model or equation in the set of data (Vogel and Todaro., 1997).

Table 6 Analysis of variance (ANOVA) for the response surface secondorder polynomial model for the yield of $S$. mahagoni seed obtained by $\mathrm{SC}-\mathrm{CO}_{2}$ extraction

\begin{tabular}{ccccc}
\hline Source & $\begin{array}{c}\text { Sum of } \\
\text { squares }\end{array}$ & $\begin{array}{c}\text { Degree of } \\
\text { freedom }\end{array}$ & $\begin{array}{c}\text { Mean } \\
\text { square }\end{array}$ & $\mathrm{F}_{\text {calculated }}$ \\
\hline $\begin{array}{c}\text { Due to } \\
\begin{array}{c}\text { Regression } \\
\text { Residual } \\
\text { Total }\end{array}\end{array}$ & 107.66 & 5 & 21.53 & 23.08 \\
\hline
\end{tabular}

Table 7 Analysis of variance (ANOVA) for the response surface secondorder polynomial model for $\beta$-sitosterol obtained by $\mathrm{SC}-\mathrm{CO}_{2}$ extraction

\begin{tabular}{ccccc}
\hline Source & $\begin{array}{c}\text { Sum of } \\
\text { squares }\end{array}$ & $\begin{array}{c}\text { Degree of } \\
\text { freedom }\end{array}$ & $\begin{array}{c}\text { Mean } \\
\text { square }\end{array}$ & $\mathbf{F}_{\text {calculated }}$ \\
\hline $\begin{array}{c}\text { Due to } \\
\begin{array}{c}\text { Regression } \\
\text { Residual } \\
\text { Total }\end{array}\end{array}$ & 0.35 & 5 & 0.069 & 7.81 \\
\hline
\end{tabular}

Based on the analysis of variance for both oil yield and $\beta$-sitosterol content fitted in the second-order polynomial model, the calculated Fvalues are 23.08 and 7.81, respectively. To determine the significant of the calculated F-values obtained, the tabulated F-values from the table of the critical value of $\mathrm{F}$ with 0.05 of significance level were compared. Thereby, the calculated F-value obtained are greater than tabulated $F_{(5,7,0.05)}$ obtained which is 3.97 . It indicates the significance between independent variables with the responses at $95 \%$ confidence level. Hence, second-order polynomial model was chosen to depict the relationship between the oil yield and $\beta$-sitosterol content with the independent variables (temperature and pressure) The second-order polynomial model equations for oil yield, $\mathrm{Y}_{1}$, and $\beta$-sitosterol content, $\mathrm{Y}_{2}$ (dependent variables), with pressure, $\mathrm{X}_{1}$, and temperature, $\mathrm{X}_{2}$, (independent variables) are shown in Eq. (3) and (4), respectively:

$Y_{1}=125.7830-5.3882 X_{1}+0.0575 X_{1}^{2}-2.4506 X_{2}+0.0089 X_{2}^{2}+$ $0.0625 X_{1} X_{2}$

$Y_{2}=-3.0321+0.5881 X_{1}-0.0088 X_{1}^{2}-0.1628 X_{2}+0.0023 X_{2}^{2}+$ $0.0025 X_{1} X_{2}$

The multiple regression coefficients (individual linear, quadratic and interaction terms) of the oil yield and $\beta$-sitosterol content were determined and summarized in Figure 7 and 8, respectively, together with the Pareto charts. Regression coefficients indicate the ability of any term(s) toward the response variable(s) (Mironeasa et al., 2016). All the terms in the polynomial were analyzed by the degree of significance ( $p$-value) of each term. Thus, the term that is considered significant $(p<0.05)$ has an influenced on the process (Cvjetko., 2012).

Based on Fig. 7, the oil yield regression coefficients were significant except for temperature in quadratic $\left(\mathrm{X}_{2}^{2}\right)$ and linear terms $\left(\mathrm{X}_{2}\right)$ with $p>0.05$. Therefore, the temperature has no influence on the oil extraction. The pressure in a linear term $\left(\mathrm{X}_{1}\right)$ showed a negative effect on the response (oil yield) with $p<0.05$. While the pressure in the quadratic term $\left(\mathrm{X}_{1}^{2}\right)$ and interaction of pressure and temperature term $\left(\mathrm{X}_{1} \mathrm{X}_{2}\right)$ gave a positive effect on oil yield with $p>0.05$ and $p>0.01$, respectively. Hence, pressure is a dominant factor on the oil yield. The solvent density increases with increasing pressure hence the interaction of inter-molecules and solutes increase (Pereira and Meireles., 2009).

\begin{tabular}{|c|c|}
\hline Variable(s) & $\begin{array}{c}\text { Regression coefficients } \\
\text { estimation }\left(0 \text { il yield, } \mathrm{Y}_{1}\right)\end{array}$ \\
\hline Intercept & $125.7830^{\mathrm{a}}$ \\
\hline $\mathrm{X}_{1}$ & $-5.3882^{\mathrm{b}}$ \\
\hline $\mathrm{X}_{l^{2}}$ & $0.0575^{\mathrm{b}}$ \\
\hline $\mathrm{X}_{2}$ & -2.4506 \\
\hline $\mathrm{X}_{2}{ }^{2}$ & 0.0089 \\
\hline $\mathrm{X}_{\mathrm{X}} \mathrm{X}_{2}$ & $0.0625^{\mathrm{a}}$ \\
\hline${ }^{2} p<0.01$, & ${ }^{b} p<0.05$. \\
\hline
\end{tabular}

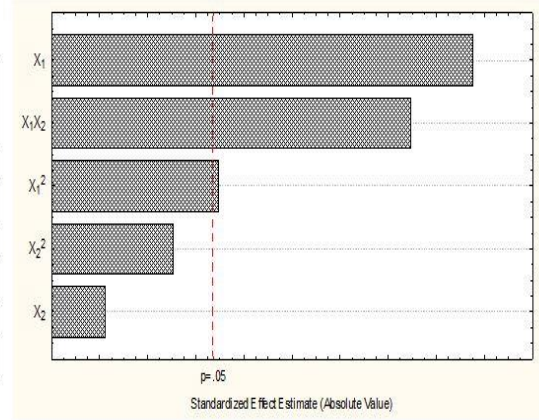

Fig. 7 Multiple regression coefficients and Pareto chart of the oil yield

Pareto chart in statistical analysis is used to demonstrate the effect of the factor to the response (Nei et al., 2009). When the bars that represent each independent variables exceeding the line at $p=0.05$ indicate that the independent variables are significant at $95 \%$ confidence level (Rodriguez-Nogales et al., 2005). Based on the Pareto chart, the most influence independent variable is pressure in a linear term $\left(\mathrm{X}_{1}\right)$, meanwhile to least influence is pressure in a quadratic term $\left(\mathrm{X}_{1}^{2}\right)$. The temperature in a linear term $\left(\mathrm{X}_{2}\right)$ is not significance to the response.

Subsequently, the regression coefficients for $\beta$-sitosterol content in Fig. 8 also shows that all the terms were significant except for temperature in a linear term $\left(\mathrm{X}_{2}\right)$ with $p>0.05$ and temperature in a quadratic term $\left(\mathrm{X}_{2}^{2}\right)$ with $p>0.01$. Thus, the temperature in linear and quadratic terms do not affect the $\beta$-sitosterol concentration. The pressure in quadratic $\left(\mathrm{X}_{1}^{2}\right)$ and interaction of pressure and temperature $\left(\mathrm{X}_{1} \mathrm{X}_{2}\right)$ terms shows a positive effect on $\beta$-sitosterol concentration with 
$p>0.01$ and $p>0.05$, respectively. Inversely, the pressure in a linear term $\left(\mathrm{X}_{1}\right)$ shows the negative effect on $\beta$-sitosterol content with $p$ $>0.05$. Hence, pressure in the recovery of $\beta$-sitosterol is crucial.

\begin{tabular}{|c|c|}
\hline Variable(s) & $\begin{array}{c}\text { Regression coefficients } \\
\text { estimation ( }(\text {-sitosterol } \\
\left.\text { concentration, } \mathrm{Y}_{2}\right)\end{array}$ \\
\hline Intercept & $-3.0321^{\mathrm{a}}$ \\
\hline $\mathrm{X}_{1}$ & $0.5881^{\mathrm{b}}$ \\
\hline $\mathrm{X}_{1}{ }^{2}$ & $-0.0088^{\mathrm{a}}$ \\
\hline $\mathrm{X}_{2}$ & -0.1629 \\
\hline $\mathrm{X}_{2}{ }^{2}$ & $0.0023^{2}$ \\
\hline $\mathrm{X}_{1} \mathrm{X}_{2}$ & $-0.0025^{\mathrm{b}}$ \\
\hline${ }^{2} p<0.01, \quad{ }^{b} p<0.05$. \\
\hline
\end{tabular}

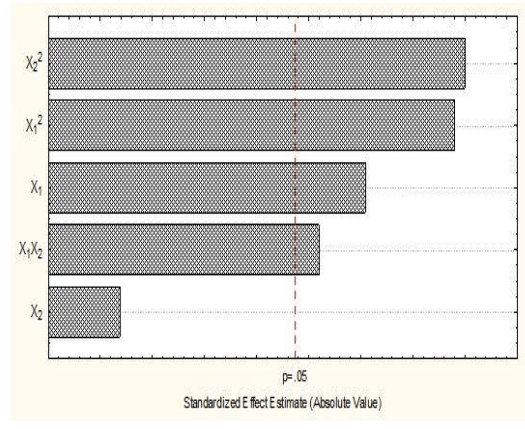

Fig. 8 Multiple regression coefficients and Pareto chart of the $\beta$-sitostero content

Pressure is significant to the recovery of $\beta$-sitosterol. Theoretically, by increasing the pressure, the density of solvent also increase (Pereira and Meireles., 2009, Liza et al., 2010). This will also enhance the solvating power and increase the solute solubility (Pereira and Meireles., 2009) resulting in a higher recovery of $\beta$-sitosterol. Based on the Pareto chart, the most influence independent variable is the pressure in a quadratic term $\left(\mathrm{X}_{1}{ }^{2}\right)$. Whereas, the temperature in a linear term $\left(\mathrm{X}_{2}\right)$ and temperature in a quadratic term $\left(\mathrm{X}_{2}^{2}\right)$ are not significance to the response.

\section{Analysis of response surface}

Fig. 9 show the surface plot for the response of the oil yield. When the temperature decreases from $60-40^{\circ} \mathrm{C}$, the oil yield slightly increases, while as pressure increases from 20-30 MPa, the oil yield increases. It concluded that pressure is a dominant factor for the extraction of oil yield from Swietenia mahagoni seeds, whereas temperature has a minimal effect on the oil yield. According to Qiuhui et al., (2007), the extraction of Chlorella pyrenoidosa resulted in the increase of oil yield as pressure increase from 25 to $40 \mathrm{MPa}$ due to the change in solubility of oil in $\mathrm{SC}-\mathrm{CO}_{2}$. The increase in solubility of oil in the solvent will increase the extraction rate because of the solvating power. De-Castro et al., (1994) stated solvating power is the interaction of intermolecular solvent and solute.

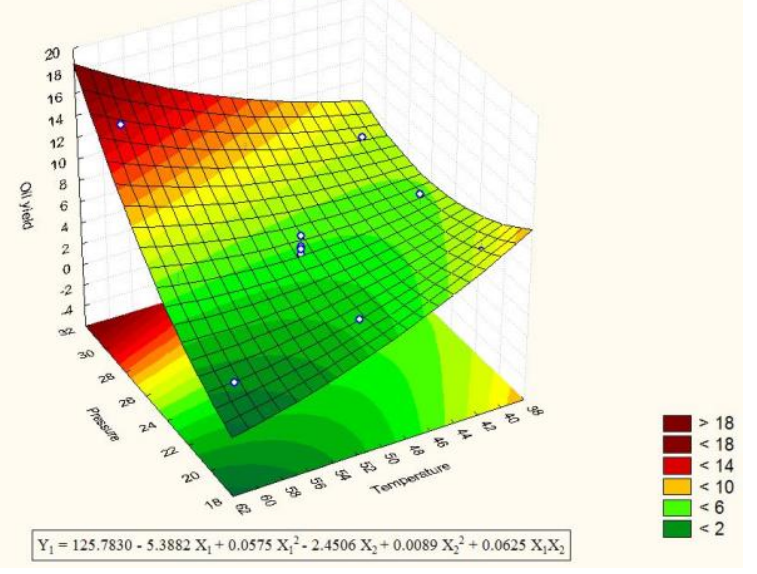

Fig. 9 Surface plot of oil yield from S. mahagoni as a function of pressure and temperature

In addition, Mustapa et al., (2009) reported that the increase in intermolecular interactions of solvent and solute resulted in the increase of solvent density, thereby the extraction rate increases. Similar finding was reported by de Azevedo et al., (2008), the extraction of green coffee oil ranging pressures from 15.2 to $35.2 \mathrm{MPa}$ found that the extraction rate correlates with the increase in solvent density. The authors added that pressure also attributed to the increase in solvating power and the intermolecular physical interactions between solvent and solute.

Moreover, similar trends were reported in the extraction of Vitex agnus castus (Cossuta et al., 2008) and virgin coconut oil (Nik Norulaini et al., 2009) where the extraction rate increases as pressure increases due to the solvent power. In the extraction of Vitex agnus castus fruit at the pressure of 10 to $45 \mathrm{MPa}$ increased the extraction rate. The authors also related the solubility parameter in the study with the solvent power of $\mathrm{SC}-\mathrm{CO}_{2}$ that increased significantly as the pressure increased from 10 to $27.5 \mathrm{MPa}$. Meanwhile, the effect of pressure in the extraction of virgin coconut oil found that yield obtained also depended on the pressure, where a $100 \%$ oil yield was obtained at the highest pressure.

The study of the extraction of bottle gourd seed oil by Said et al., (2014) reported that the direct relationship of pressure and $\mathrm{SC}-\mathrm{CO}_{2}$ gave the dominant effect of pressure toward the mass transfer rate as well as the extraction rate. Viganó et al., (2016) stated that the recovery of extraction yield is related to the solvent power where the increase in pressure at constant temperature resulted in the increase of extraction yield due to the increase of $\mathrm{CO}_{2}$ density as well as solvent power.

Subsequently, the minimal effect of temperature in the extraction of Swietenia mahagoni seeds as the drop of temperature from $60-40^{\circ} \mathrm{C}$, increases the extraction yield. This phenomena can be related to the study of Lee et al., (1991), where the solvent solubility increased at the lower temperature due to the changes in density. Jerry et al., (2001) also reported that the maximum oil yield was extracted at lower temperature in the extraction of Vernonia galamensis seeds. This is due to the increase in density of extraction fluid $\left(\mathrm{SC}-\mathrm{CO}_{2}\right)$ when the temperature decreases from $100-40^{\circ} \mathrm{C}$.

Azizi et al., (2007) reported the similar result in the extraction of Parkia Speciosa seeds using $\mathrm{SC}-\mathrm{CO}_{2}$. The oil yield decreased as the temperature increased due to the retrograde vaporization behavior. This behavior referred to the increase in the solvent solubility at lower temperature up to cross over pressure zone as the density increases. Meanwhile, in the extraction of Vitex agnus castus fruit by Cossuta et al., (2008) found that as temperature increases, the solubility parameter also decreases as well as the extraction yield. Solubility parameter in the author's study refer to the relative solvency behavior of $\mathrm{SC}-\mathrm{CO}_{2}$. This finding can be related to the study in the extraction of passion fruit bagasse by Viganó et al., (2016), where the reduction in oil yield as temperature increase because of the density of $\mathrm{CO}_{2}$ decrease.

Fig. 10 shows the response surface plot of $\beta$-sitosterol content as a function of pressure and temperature. The effect of pressure on the extraction of $\beta$-sitosterol shows a positive quadratic effect. As pressure increases from 20 to $25 \mathrm{MPa}$, the $\beta$-sitosterol content in extract increases as the solubility of $\beta$-sitosterol in the solvent but decreases as it reaches $30 \mathrm{MPa}$, which shows the interaction of repulsive solutesolvent increases (Liu et al., 2009). This may be due to the compressed solvent at high pressure in the extractor.

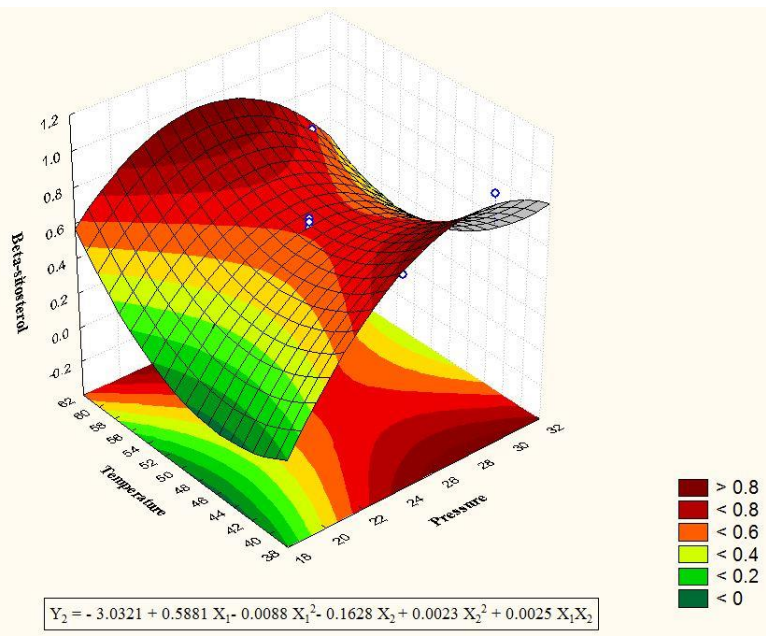

Fig. 10 Surface plot of $\beta$-sitosterol content from $S$. mahagoni as a function of pressure and temperature 
Similar finding reported by Hartati et al., (2014) in the extraction of Swietenia mahagoni seeds. The negative quadratic effect at high pressure is resulted from the highly compressed $\mathrm{CO}_{2}$ that facilitates solute-solvent repulsion. The authors suggested that high pressure is not always recommended because it can potentially induce the complex extraction. Catchpole et al., (2002) performed the extraction of $\beta$ sitosterol from saw palmetto berries at the pressure of 25 and $28 \mathrm{MPa}$ and at the temperature of $40^{\circ} \mathrm{C}$. The highest concentration of $\beta$ sitosterol found in the extract was at $28 \mathrm{MPa}$ and $40^{\circ} \mathrm{C}$.

According to Cossuta et al., (2008), the increase of the pressure slightly increased the yield of the $\beta$-sitosterol. Pressure had the strongest effect on the concentration of phytostreol in roselle seed (Nyam et al., 2010). At high pressure, the $\mathrm{CO}_{2}$ density increases hence the solvent power to dissolve the analyte also increases (Machmudah et al., 2007). On the other hand, at higher temperature, the concentration of $\beta$-sitosterol decrease in both studies. Similarly, the concentration of $\beta$-sitosterol decreased with an increase in temperature of $40-80^{\circ} \mathrm{C}$ in Kalahari melon seed oil (Nyam et al., 2010).

The evaluation of the effect of temperature toward the extraction of $\beta$-sitosterol is much more complex due to the dual effects. In the Fig. 10 , it shows the negative quadratic effect of temperature. Dual effects of temperature are when the temperature at $40^{\circ} \mathrm{C}$ to $50^{\circ} \mathrm{C}$, the decrease in $\beta$-sitosterol content due to the reduce in the solubility of $\beta$-sitosterol in the solvent but as temperature further increasing to $60^{\circ} \mathrm{C}$, the $\beta$ sitosterol content in the extract increases. This is because of the mass transfer of $\beta$-sitosterol in the solvent as the solubility of mentioned analyte increases.
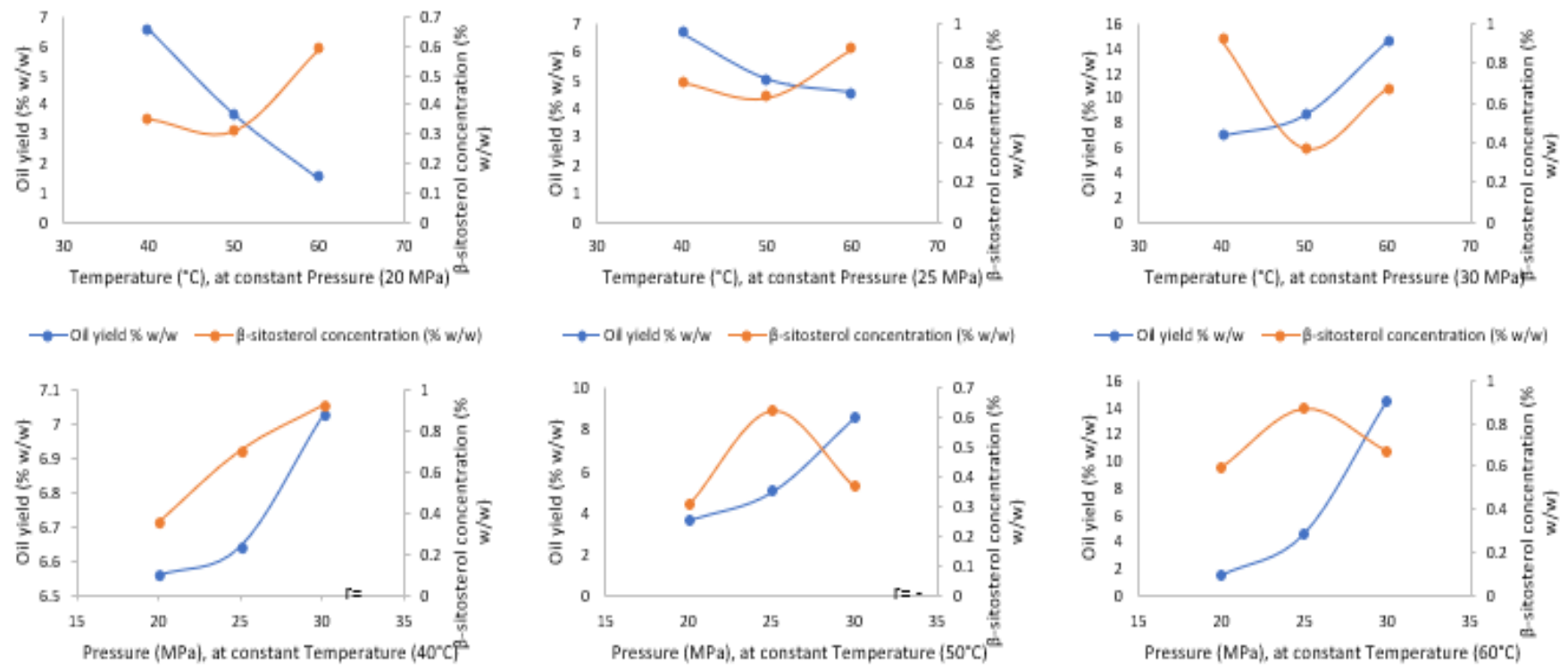

Fig. 11 The correlation of oil yield and $\beta$-sitosterol content in the extracts

\section{Correlation of oil yield and $\boldsymbol{\beta}$-sitosterol}

Moreover, several studies had suggested the act of oil as co-solvent in the extraction of compound (Vasapollo et al., 2004, Sun et al., 2006, Krichnavaruk et al., 2008, Viganó et al., 2016). Thus, the correlation of oil yield and $\beta$-sitosterol content of extracts was examined as shown in Fig. 11. At the constant pressure of 25 and $30 \mathrm{MPa}$, it shows no correlation between extraction of oil yield and $\beta$-sitosterol content since $\mathrm{r}$ value is nearer to zero. On the contrary, at the constant pressure of 20 $\mathrm{MPa}$ it shows a negative correlation. A negative correlation means that the oil yield decreases, while the $\beta$-sitosterol content increases. This result is the opposite as the other studies mentioned. This may be due to the low pressure of extraction led to the decrease in the density of the fluid due to the distance between the molecules, that resulted in reduce in the solubility of $\beta$-sitosterol content.

Meanwhile, at the constant temperature of $50^{\circ} \mathrm{C}$ and $60^{\circ} \mathrm{C}$ it shows no correlation between extraction of the oil yield and the $\beta$-sitosterol content, however at the constant temperature of $40^{\circ} \mathrm{C}$, the $\mathrm{r}$ value is 0.88 that shows a positive correlation. A positive correlation means that the oil yield increases, and the $\beta$-sitosterol content also increases. This shows that the domination of solute vapor pressure at low temperature (Kawahito et al., 2008). Hence, it is proven that the influence of extracted oil as co-solvent in $\mathrm{SC}-\mathrm{CO}_{2}$ was influenced by pressure and temperature in the extraction of the compound.

\section{CONCLUSION}

Supercritical carbon dioxide $\left(\mathrm{SC}-\mathrm{CO}_{2}\right)$ extraction applied to extract $\beta$-sitosterol from Swietenia mahagoni seeds shows that pressure and temperature influenced the extraction of $\beta$-sitosterol. The maximum yield of the extract was $14.45 \%$ obtained at $30 \mathrm{MPa}$ and $60^{\circ} \mathrm{C}$, and the maximum of $\beta$-sitosterol content was $0.9204 \%$ obtained at $30 \mathrm{MPa}$ and $40^{\circ} \mathrm{C}$. This work is the first to report the quantification of $\beta$-sitosterol from Swietenia mahagoni seeds and had succedded in obtaining the optimized parameters for obtaining highest valued of $\beta$-sitosterol from Swietenia mahagoni seeds.

\section{ACKNOWLEDGEMENT}

The authors are highly grateful to the financial support from Universiti Teknologi Malaysia for the Research University Grant Scheme, GUP (Q.J130000.2546.12H93 and Q.J130000.2546.16H97). The authors would also like to acknowledge the technical and management support from Research Management Centre (RMC), Universiti Teknologi Malaysia.

\section{REFERENCES}

Aionicesei, E., Škerget, M., and Knez, Ž. 2008. Measurement of $\mathrm{CO}_{2}$ solubility and diffusivity in poly(1-lactide) and poly(d,1-lactide-co-glycolide) by magnetic suspension balance. J. Supercri. Fluids. 47, 296-301.

Andras, C. D., Simandi, B., Orsi, F., Lambrou, C., Missopdinou-Tatala, D., Panayiotou, C., Dmokus, J., and Doleschall, F. 2005. Supercrtical carbon dioxide extraction of okra (Hibiscus esculentus L.) seeds. J. Sci. Food. Agri. 85, 1415-1419.

Balijepalli. M. K., Suppaiah, V., Chin, A. M., Buru, A. S., Saqineedu, S. R., and Pichika, M. R. 2014. Acute oral toxicity studies of Swietenia macrophylla seeds in sprague dawley rats. Pharmacognosy Res. 7, 38-44.

Bezerra, M. A., Santelli, R. E., Oliveira, E. P., Villar, L. S., and Escaleira, L. A. 2008. Response surface methodology (RSM) as a tool for optimization in analytical chemistry. Talanta. 76, 965-977. 
Blundell, A. G., and Gullison, R. E. 2003. Poor regulatory capacity limits the ability of science to influence the management of mahogany. For. Policy Econ. 5, 395-405.

Catchpole, O. J., Perry, N. B., Da Silva, B. M. T., Grey, J. B., and Smallfield, B. M. 2002. Supercritical extraction of herbs I: Saw Palmetto, St John's Wort, Kava root, and Echinacea. J. Supercrit. Fluids. 22, 129-138.

Cossuta, D., Simandi, B., Vagi, E., Hohmann, J., Prechl, A., Lemberkovics, E., Kery, A., and Keve, T. 2008. Supercritcal fluid extraction of Vitex agnus castus fruit. J. Supercrit. Fluids. 47, 188-194.

Cvjetko, M. 2012. Optimization of the supercritical $\mathrm{CO}_{2}$ extraction of oil from rapeseed using response surface methodology. Food Technology and Biotechnology. 50, 2, 208-215.

De Azevedo, A. B. A., Mazzafera, P., Mohamed, R. S., Vieira De Melo, S. A B., Kieckbusch, T. G. 2008. Extraction of caffeine, cholorogenic acids and lipids from green coffee beans using supercritical carbon dioxide and cosolvents. Brazilian J. Chem. Eng. 25, 543-552.

Eid, A. M. M., Elmarzugi, N. A., El-Enshasy, H. A. 2013. A review on the phytopharmacological effect of Swietenia macrophylla. Int. J. Pharma. Sci. 5 , 47-53.

Falah, S., Suzuki, T., Katayama, T. 2008. Chemical constituents from Swietenia macrophylla bark and their antioxidant activity. Pakistan J. Biol. Sci. 11, 2007-2012

Goh, B. H., Abdul Kadir, H., Abdul Malek, S., Ng, S.W. 2010. Swietenolide diacetate from the seeds of Swietenia macrophylla. Acta Crystallogr. Sect. E Struct. Report Online. 66, 6, o1396.

Goh, B. H., and Kadir, H. A. 2011. In vitro cytotoxic potential of Swietenia macrophylla King seeds against human carcinoma cell lines. J. Med. Plants Res. 5, 1395-1404.

Hartati, Salleh, L. M., Mohd Yunus, A. C., and Aziz, A. A. 2014. Optimization of supercritical $\mathrm{CO}_{2}$ extraction of Swietenia mahagoni seed by response surface methodology. J. Teknol. 67, 15-20.

Hashim, M. A., Yam, M. F., Hor, S. Y., and Lim, C. P. 2013. Antihyperglycemic activity of Swietenia macrophylla King (meliaceae) seed extracts in normoglycaemic rats undergoing glucose tolerance test. Chin. Med. 8,11 .

Haque, M. A., Khan, G. M. A., Razzaque, S. M. A., Khatun, K., Chakraborty, A. K., and Alam, M. S. 2013. Extraction of rubiadin dye from Swietenia mahagoni and its dyeing characterictics onto silk fabric using metallic mordants. Indian J. Fibre Text. Res. 38, 280-284.

Henika. R. G. 1982. Use of response-surface methodology in sensory evaluation. Food Technology. 36, 96-100.

Hu, Q., Pan, B., Xu, J., Sheng, J., and Shi, Y. 2007. Effects of supercritical carbon dioxide extraction conditions on yields and antioxidant activity of Chlorella pyrenoidosa extracts. J. Food Eng. 80, 997-1001.

Kawahito, Y., Kondo, M., Machmudah, S., Sibano, K., Sasaki, M., and Goto, M. 2008. Supercritical $\mathrm{CO}_{2}$ extraction of biological active compounds from loquat seed. Sep. Purif. Technol. 61, 130-135.

King, J. W., Mohamed, A., Taylor, S. L., Mebrahtu, T., and Paul, C. 2001 Supercritical fluid extraction of Vernonia galamensis seeds. Ind. Crops Prod. 14, 241-249.

Krichnavaruk, S., Shotipruk, A., Goto, M., and Pavasant, P. 2008. Supercritica carbon dioxide extraction of astaxanthin from Haematococcus pluvialis with vegetable oils as co-solvent. Bioresour. Technol. 99, 5556-5560.

Lee, B. C., Kim, J. D., Hwang, K. Y., and Lee, Y. Y. 1991. Extraction of oil from evening primrose seed with supercritical carbon dioxide. Supercrit. Fluid Process. Biomater. 168-180.

Liu, S., Yang, F., Zhang, C., Ji, H., Hong, P., and Deng, C. 2009. Optimization of parameters for supercritical carbon dioxide extraction of Passiflora seeds oil by response surface methodology. J. Supercrit. Fluids. 48, 9-14.

Liza, M. S., Abdul Rahman, R., Mandana, B., Jinap, S., Rahmat, A., Zaidul, I. S. M. and Hamid, A. 2010. Supercritical carbon dioxide extraction of bioactive flavonoid from Strobilanthes cripus (Pecah kaca). Food Bioprod. Process. 88, 319-326.

Luque de Castro, M. D., Valcarcel, M., and Tena, M. T. 1994. Analytical Supercritical Fluid Extraction, Germany: Springer-Verlag.

Machmudah, S., Kawahito, Y., Sasaki, M., and Goto, M. 2007. Supercritical $\mathrm{CO}_{2}$ extraction of rosehip seed oil: Fatty acids composition and process optimization. J. Supercrit. Fluids. 41, 421-428.
Maiti, A., Dewanjee, S., Kundu, M., and Mandal, S. C. 2009. Evaluation of antidiabetic activity of the seeds of Swietenia macrophylla in diabetic rats. Pharma. Biol. 47, 132-136.

Mironeasa, S., Codină, G. G., and Mironeasa, C. 2016. Optimization of wheatgrape seed composite flour to improve alpha-amylase activity and dough rheological behavior. Int. J. Food. Prop. 19, 859-872.

Mohd Azizi, C. Y., Salman, Z., Nik Norulaini, N. A., and Mohd Omar, A. K. 2007. Extraction and identification of compounds from Parkia speciose seeds by supercritical carbon dioxide. J. Chem. Nat. Resour. Eng. Spec. Ed. $153-$ 163.

Mustpha, A. N., Manan, Z. A., Mohd Azizi, C. Y., Nik Norulaini, N. A., and Omar, A. K. M. 2009. Effects of parameters on yield for sub-critical R134a extraction of palm oil. J. Food Eng. 95, 606-616.

Nei, H. Z. N., Fatemi, S., Salimi, A. R., Vatanara, A., and Najafabadi, A. R. 2009. Enrichment of omega 3 fatty acids from Tyulka oil by supercritical $\mathrm{CO}_{2}$ extraction. J. Chem. Technol. Biotechnol. 84, 1854-1859.

Nik Norulaini, N. A., Setianto, W. B., Zaidul, I. S. M., and Nawi, A. H. 2009. Effects of supercritical carbon dioxide extraction parameters on virgin coconut oil yield and medium-chain triglyceride content. Food Chem. 116, 193-197.

Nyam, K. L., Tan, C. P., Karim, R., Lai, O. M., Long, K., and Che Man, Y. B. 2010. Extraction of tocopherol-enriched oils from Kalahari melon and roselle seeds by supercritical fluid extraction $\left(\mathrm{SFE}-\mathrm{CO}_{2}\right)$. Food Chem. 119, 1278 1283 .

Nyam, K. L., Tan, C. P., Lai, O. M., Long, K., and Che Man, Y. B. 2010. Optimization of supercritical fluid extraction of phytosterol from roselle seeds with a central composite design model. Food Bioprod. Process. 88, 239-246.

Pereira, C. G., and Meireles, M. A. A. 2009. Supercritical fluid extraction of bioactive compounds: Fundamentals, application and economic perspectives. Food Bioprocess Technol. 3, 340-372.

Rastogi, N. K., and Rashmi, K. R. 1999. Optimization of enzymatic liquefaction of mango pulp by response surface methodology. Eur. Food. Res. Technol. 209, 57-62.

Rodriguez-Nogales, J. M., Roura, E., and Contreras, E. 2005. Biosynthesis of ethyl butyrate using immobilized lipase: A statistical approach. Process Biochem. 40, 63-68.

Said, P. P., Sharma, N., Naik, B., and Pradhan, R. C. 2014. Effect of pressure, temperature and flow rate on supercritical carbon dioxide extraction of bottle gourd seed oil. Int. J. Food. Nutr. Sci. 3, 14-17.

Sánchez-Machado, D. I., López-Hernández, J., Paeiro-Losada, P., and LópezCervantes, J. 2004. An HPLC method for the quantification of sterols in edible seaweeds. Biomed. Chromatogr. 18, 183-190.

Sajfrtová, M., Licková, I., Wimmerová, M., Sovová, H., and Wimmer, Z. 2010. $\beta$-Sitosterol supercritical carbon dioxide extraction from sea buckthorn (Hippophae rhamnoides L.) seeds. Int. J. Mol. Sci. 11, 1842-1850.

Sharif, K. M., Rahman, M. M., Azmir, J., Mohamed, A., Jahuru, M. H. A., Sahena, F., Zaidul, I. S. M. 2014. Experimental design of supercritical fluid extraction - A review. J. Food Eng. 124, 105-116.

Simandi, B., Kristo, S. T., Kery, A., Selmeczi, L. K., Kmecz, I., and Kemény, S. 2002. Supercritical fluid extraction of dandelion leaves.

Sin, H. N., Yusof, S., Hamid, N. S. A., and Rahman, R. A. 2006. Optimization of enzymatic clarification of sapodilla juice using response surface methodology. J. Food. Eng. 73, 313-319.

Sun, M., and Temelli, F. 2006. Supercritical carbon dioxide extraction of carotenoids from carrot using canola oil as a continuous co-solvent. $J$. Supercrit. Fluids. 37, 397-408.

Vasapollo, G., Longo, L., Rescio, L., and Ciurlia, L. 2004. Innovative supercritical $\mathrm{CO}_{2}$ extraction of lycopene from tomato in the presence of vegetable oil as co-solvent. J. Supercrit. Fluids. 29, 87-96.

Viganó, J., Coutinho, J. P., Souza, D. S., Baroni, N. A. F., Helena, T. G., Juliana, A., and Julian, M. 2016. Exploring the selectivity of supercritical $\mathrm{CO}_{2}$ to obtain nonpolar fractions of passion fruit bagasse extracts. J. Supercrit. Fluids. 100, 1-10.

Vilegas, J. H. Y., de Marchi, E., and Lancas, F. M. 1997. Extraction of low polarity compounds (with emphasis on coumarin and kaurenoic acid) from Mikania glomerata ("guaco") leaves. Phytochem. Anal. 8, 266-270.

Vogel, H. C., and Todaro, C. L. 1997. Fermentation and Biochemical Engineering Handbook. ( $3^{\text {rd }}$ ed.). Westwood, New Jersey, U.S.A. Elsevier Inc. 